\title{
Physical and Magnetic Properties of Barium Calcium Hexaferrite Nano- particles Synthesized by Water-in-oil Reverse Micelle and Co-precipitation Techniques
}

\author{
R. B. Jotania ${ }^{1 *}$, R. B. Khomane ${ }^{2}$, A. S. Deshpande ${ }^{2}$, C. C. Chauhan ${ }^{1}$, and B. D. Kulkarni ${ }^{2}$ \\ ${ }^{1}$ Department of Physics, University School of Sciences, Gujarat University, Ahmedabad 380 009, \\ Gujarat, India \\ ${ }^{2}$ Chemical Engineering and Process Development Division, National Chemical Laboratory, \\ Dr. Homi Bhabha Marg, Pune 411 008, Maharashtra, India
}

Received 5 September 2008, accepted in final form 25 October 2008

\begin{abstract}
$\mathrm{BaCa}_{2} \mathrm{Fe}_{16} \mathrm{O}_{27}$ hexaferrite particles were prepared using two different techniques namely (i) reverse micelle and (ii) co-precipitation with and without presence of surfactants (cationic, anionic and nonionic). The precipitate was calcinated at $950^{\circ} \mathrm{C}$ for 4 hours and characterized by using various instrumental techniques. The structural studies of the samples were studied by using XRD and SEM. The field dependent magnetic properties of prepared $\mathrm{Ba}-\mathrm{Ca}$ hexaferrite powder was investigated at room temperature by using vibrating sample magnetometer. It has been observed that the type of surfactant plays a crucial role in deciding the morphology of the particles. There is significant change in crystallite size of the resultant $\mathrm{Ba}-\mathrm{Ca}$ hexaferrite prepared in presence of anionic surfactant sodium dodecyl sulfate (SDS) and reverse micelle route. The samples prepared in presence of cationic and non ionic surfactants show agglomerated large particles. Magnetic study reveals that the value of anisotropy constant $(\mathrm{K})$ depends on the type of surfactant used. The sample prepared in presence of nonionic surfactant Polyethylene glycol sorbitan monooleate (Tween 80) shows low anisotropy constant $\left(0.26 \times 10^{-3} \mathrm{HA}^{2} / \mathrm{kg}\right)$ where as the sample prepared in presence of SDS surfactant exhibits high anisotropy constant $\left(3.26 \times 10^{-3} \mathrm{HA}^{2} / \mathrm{kg}\right)$ compared to normal sample $\left(0.41 \times 10^{-3} \mathrm{HA}^{2} / \mathrm{kg}\right)$.
\end{abstract}

Keywords: Barium calcium hexaferrite particles; Surfactants; Structural and magnetic properties.

(C) 2009 JSR Publications. ISSN: 2070-0237(Print); 2070-0245 (Online). All rights reserved.

DOI: $10.3329 /$ jsr.v1i1.1684

\section{Introduction}

Barium hexaferrites, a classical ferromagnetic materials are widely used in high density magnetic recording media, overcoat-free, contact or semi-contact recording media and microwave tunable devices working at high frequency, above $70 \mathrm{GHz}$ [1-5]. These materials have attracted because of excellence chemical stability, mechanical hardness

\footnotetext{
*Corresponding author: rbjotania@gmail.com
} 
and relatively strong magnetic properties like high magnetic anisotropy, high coercivity and saturation magnetization [6,7]. Hexaferrite can be classified in to six categories: M-type $\left(\mathrm{BaFe}_{12} \mathrm{O}_{19}\right), \quad$ W-type $\left(\mathrm{BaMe}_{2} \mathrm{Fe}_{16} \mathrm{O}_{27}\right), \quad \mathrm{Y}$-type $\left(\mathrm{BaMe}_{2} \mathrm{Fe}_{12} \mathrm{O}_{22}\right), \quad \mathrm{X}$-type $\left(\mathrm{Ba}_{2} \mathrm{Me}_{2} \mathrm{Fe}_{28} \mathrm{O}_{46}\right)$, U-type $\left(\mathrm{Ba}_{4} \mathrm{Me}_{2} \mathrm{Fe}_{36} \mathrm{O}_{60}\right)$ and Z-type $\left(\mathrm{Ba}_{2} \mathrm{Me}_{2} \mathrm{Fe}_{24} \mathrm{O}_{41}\right)$, where $\mathrm{Me}$ represents, divalent cations of the first transition metal group like $\mathrm{Ni}, \mathrm{Co}, \mathrm{Zn}, \mathrm{Mg}$. The crystal structure of $\mathrm{W}$-type hexagonal ferrite is very complex and can be considered as a superposition of $\mathrm{R}$ and $\mathrm{S}$ blocks along the hexagonal $\mathrm{C}$-axis with a structure of $\mathrm{RSSR} * \mathrm{~S} * \mathrm{~S} *$, where $\mathrm{R}$ is a three-oxygen-layer block with composition $\mathrm{BaFe}_{6} \mathrm{O}_{11}, \mathrm{~S}$ (spinel block) is a two-oxygen layer block with composition $\mathrm{Fe}_{6} \mathrm{O}_{8}$ and ' $*$ ' means that the respective block is turned $180^{\circ}$ around the hexagonal axis. The application of hexaferrite in high density magnetic recording media require materials with high control of homogeneity, morphology and magnetic properties resulting from their methods of preparation and heat treatments $[8,9]$. In order to obtain ultrafine particles for use in high density magnetic recording media, it is essential to find the best synthesis conditions. The glass crystallization method [10] is a classical method for producing these materials but it has some inherent disadvantages such as high sintering temperature and generation of inhomogeneous coarse particles. To avoid these drawbacks, various chemistry based methods have been proposed: The sol-gel [11], the chemical co-precipitation [12, 13] hydrothermal synthesis $[14,15]$, micro emulsion and reverse micelle $[16,17]$ and the orgo metallic precursor synthesis [18].

We have adopted chemical co-precipitation and reverse micelle techniques in order to prepare homogeneous, ultra fine and reproducible $\mathrm{BaCa}_{2} \mathrm{Fe}_{16} \mathrm{O}_{27}$ hexaferrite particles. A reverse micelle technique is defined as thermodynamically stable isotropic dispersion of an aqueous phase in a continuous oil phase, stabilized by an interfacial layer of surfactant molecules $[19,20]$. The reverse micelle technique is widely used to prepare spinel, hexa ferrites and other materials with good physical and chemical properties [21-27]. Recently, we have prepared barium calcium hexaferrite [28] by a sol-gel method in presence of different surfactants and found that the type of surfactant plays a crucial role in controlling saturation magnetization.

In the present paper, we report the physical and magnetic properties of $\mathrm{BaCa}_{2} \mathrm{Fe}_{16} \mathrm{O}_{27}$ hexaferrite particles synthesized by a chemical co precipitation with and without presence of three surfactants: Cetyl Trimethyl Ammonium Bromide (CTAB), Sodium Dodecyl Sulfate (SDS), Polyethylene glycol sorbitan monooleate (Tween 80) and a reverse micelle techniques. The effect of surfactants on the morphology and magnetic properties of $\mathrm{BaCa}_{2} \mathrm{Fe}_{16} \mathrm{O}_{27}$ hexaferrite has been studied.

\section{Experimental procedure}

\subsection{Synthesis of Barium Calcium hexaferrite}

$\mathrm{BaCa}_{2} \mathrm{Fe}_{16} \mathrm{O}_{27}$ hexaferrite particles were synthesis and characterized by using a chemical co precipitation and water-in-oil reverse micelle techniques. 
A.R. Grade Barium nitrate $\left(\mathrm{Ba}\left(\mathrm{No}_{3}\right)_{2} \cdot 6 \mathrm{H}_{2} \mathrm{O}\right)$, Calcium nitrate $\left(\mathrm{Ca}\left(\mathrm{No}_{3}\right)_{2} \mathrm{H}{ }_{2} \mathrm{O}\right)$, Ferric nitrate $\left(\mathrm{Fe}\left(\mathrm{No}_{3}\right)_{2} .9 \mathrm{H} 2 \mathrm{O}\right)(>99.9 \%)$ were used as starting materials. Stochiometric amounts of Barium nitrate, Calcium nitrate and Ferric nitrate were dissolved, one by one, in $100 \mathrm{ml}$ of de-ionized water. Ammonia solution (30\%) was added slowly in the mixture to adjust $\mathrm{pH}$ of 8 . The mixed solution was stirred for two hours and was kept at room temperature 24 hours for aging. The Barium-calcium hexaferrite precipitates was separated in a centrifuge machine at $2500 \mathrm{rpm}$ for $20 \mathrm{~min}$. The prepared precipitate washed in 1:1 mixture of methanol and acetone followed by $100 \%$ de-ionized water to remove impurities. The precipitate was dried at $100^{\circ} \mathrm{C}$ for 24 hours and calcinated at $950^{\circ} \mathrm{C}$ for 4 hours to obtain $\mathrm{BaCa}_{2} \mathrm{Fe}_{16} \mathrm{O}_{27}$ hexaferrite particles. The procedure was repeated for each of the three surfactants: Cetyl trimethyl ammonium bromide, sodium dodecyl sulfate, Polyethylene glycol sorbitan monooleate $(0.01 \mathrm{M}$ surfactant in $100 \mathrm{ml}$ deionized water) to obtain $\mathrm{BaCa}_{2} \mathrm{Fe}_{16} \mathrm{O}_{27}$ hexaferrite particles in presence of surfactants.

Preparation procedure of barium calcium hexaferrite particles by water in oil reverse micelle technique is displayed in Fig. 1, with 4-octylphenol polyethoxylate (Triton X100) as a surfactant, n-haxanol as the co surfactant, cyclohaxane as the solvent (oil phase) and aqueous solution as water phase was chosen. The aqueous phase in microemulsion-I was a solution of $0.1 \mathrm{M}$ Barium hydroxide, $0.2 \mathrm{M}$ Calcium nitrate and $1.6 \mathrm{M}$ ferric nitrate ( $5 \mathrm{ml}$ aqueous solution in $42.5 \mathrm{ml}$ microemulsion). The aqueous phase in microemulsion-II was a solution of ammonia (25\%) as the precipitant agent (5M aqueous solution of ammonia in $42.5 \mathrm{ml}$ microemulsion). In order to obtain precipitation of barium calcium hexaferrite microemulsion-II was added drop wise in microemulsion-I under vigorous stirring for $2 \mathrm{~h}$; then the solution was aged for $12 \mathrm{hrs}$. The precursor particles within the water pool of reverse micells were washed by centrifuging with anhydrous ethanol and water to remove the remaining surfactant and organic residual. The precipitate was dried at $100^{\circ} \mathrm{C}$ for 24 hours in an oven and then calcinated at $950^{\circ} \mathrm{C}$ for $4 \mathrm{hrs}$ followed by furnace cooling to room temperature.

\subsection{Characterization}

TGA curve of dried material was recorded using a thermo gravimetric analyzer model no.TGA 50 in the region of $80^{\circ} \mathrm{C}$ to $900^{\circ} \mathrm{C}$ with a rate of $10^{\circ} \mathrm{C} / \mathrm{min}$. The crystallite structures of the prepared barium calcium particles were determined on a PW $1830 \mathrm{X}$-ray diffractometer using $\mathrm{CuK}_{\alpha}$ radiation source $(\lambda=1.5405 \AA \hat{A}, 45.0 \mathrm{kV}, 50.0 \mathrm{~mA})$. The $2 \theta$ Bragg angles were scanned over a range of $20^{\circ}-80^{\circ}$. To study the particle morphology Scanning electron microscope (Make-Leo/Lica model Stereoscan 440) was used. The magnetic properties (intrinsic coercivity, saturation and remanent magnetization) of $\mathrm{BaCa}_{2} \mathrm{Fe}_{16} \mathrm{O}_{27}$ samples were measured using a vibrating sample magnetometer (VSM, EG\&G Princeton Applied Research instrument 4500). The dielectric measurements were carried out at room temperature using Hewlett-Packard 4284 LCR meter between the frequency range $100 \mathrm{~Hz}$ to $1 \mathrm{MHz}$. 


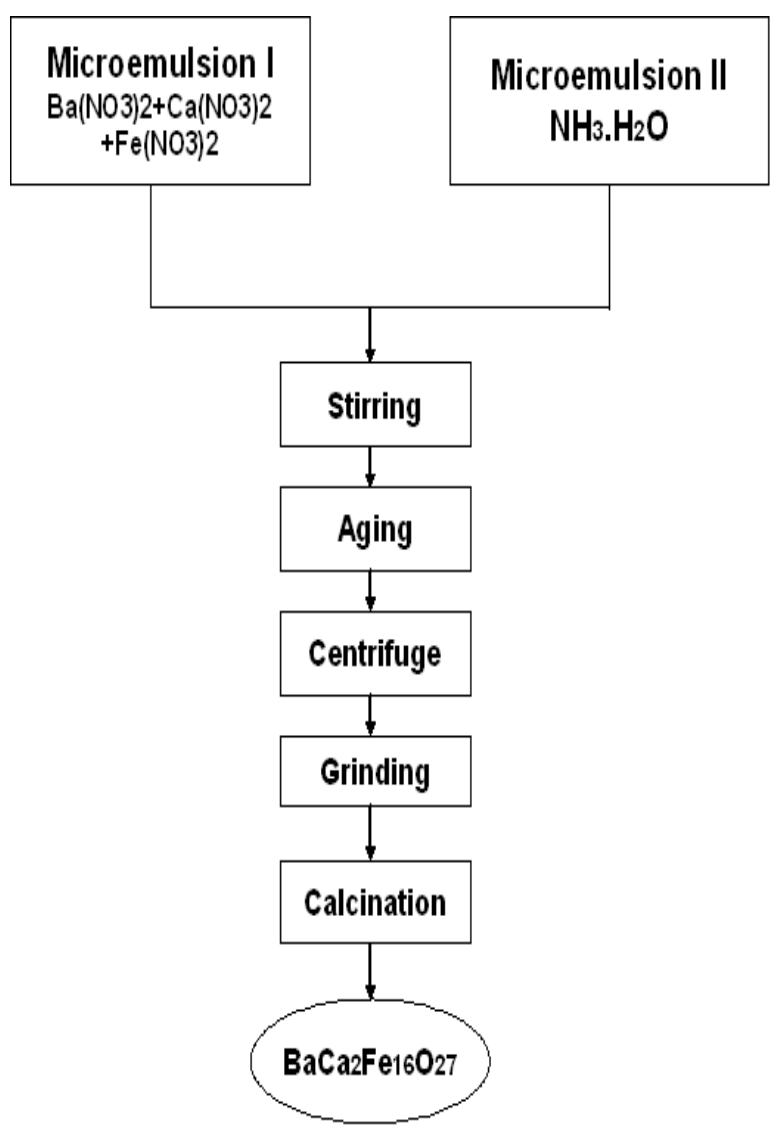

Fig. 1. Preparation of $\mathrm{BaCa}_{2} \mathrm{Fe}_{16} \mathrm{O}_{27}$ hexaferrite particles using the reverse micelle technique.

\section{Results and Discussion}

\section{1. $X$-ray diffraction analysis}

The X-ray diffraction patterns of all the samples calcinated at $950^{\circ} \mathrm{C}$ for $4 \mathrm{hrs}$ are shown in Fig. 2. The diffractogram of normal as well as surfactant samples prepared by a coprecipitation technique show the presence of $\mathrm{M}, \mathrm{W}$ and $\alpha-\mathrm{Fe}_{2} \mathrm{O}_{3}$ phases, where as the sample prepared by a reverse micelle technique shows only two phases: W-type and Mtype. It was mentioned by Lotgering et al. [29] that the unit cell of W-type phase is closely related to M-phase, only difference is that successive $\mathrm{R}$ blocks are interplaced by two S-blocks instead of one, as in the M-Phase. Moreover this W-type ferrite is chemically unstable and gets decomposed to $\mathrm{M}$ and $\alpha-\mathrm{Fe}_{2} \mathrm{O}_{3}$ phases [29-31]. 


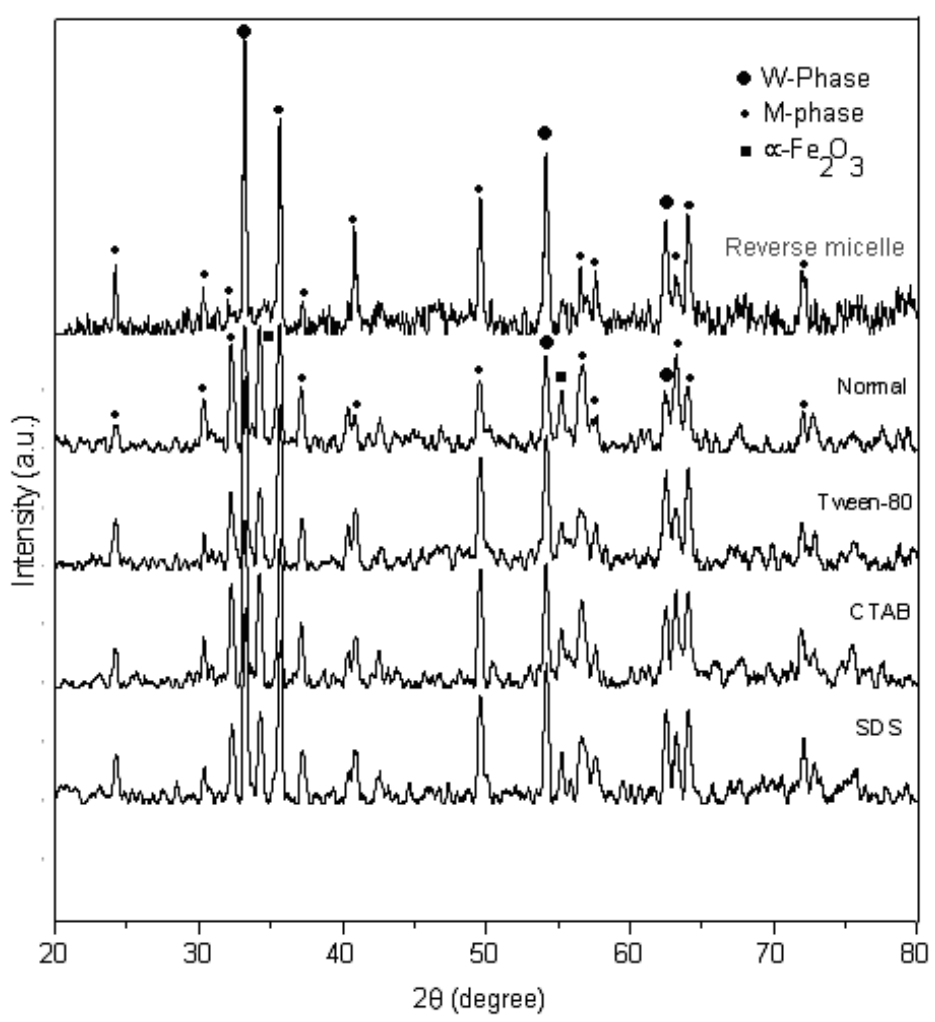

Fig. 2. The X-ray diffractogram of $\mathrm{BaCa}_{2} \mathrm{Fe}_{16} \mathrm{O}_{27}$ hexaferrite samples prepared by a coprecipitation and the reverse micelle techniques.

Lattice constants $a$ and $c$ of hexagonal barium calcium hexaferrite were calculated using Eq. (1):

$$
\frac{1}{d^{2}}=\frac{4}{3} \frac{\left(h^{2}+k^{2}+l^{2}\right)}{a^{2}}+\frac{l^{2}}{c^{2}}
$$

where $h, k$ and $l$ are Miller indices, $d$ is inter planer distance. Lattice volume of all the samples can be obtained using Eq. (2):

$$
V=\frac{(\sqrt{3})}{2} a^{2} c
$$

Table 1 shows lattice constants $a, c$ and cell volume $V$ of hexagonal $\mathrm{BaCa}_{2} \mathrm{Fe}_{16} \mathrm{O}_{27}$ prepared by a co-precipitation and the reverse micelle processes. The presence of surfactant leads to decrease in $a$ but an increase in $c$, which results in a very small change in lattice volume $V$. 
Table 1. Structure parameters $a$ and $c$ and cell volume $V$ for Barium Calcium hexaferrite samples calcinated at $950^{\circ} \mathrm{C}$ for $4 \mathrm{hrs}$.

\begin{tabular}{lcccc}
\hline $\begin{array}{l}\text { Preparation } \\
\text { route }\end{array}$ & $\begin{array}{c}\text { Surfactant } \\
\text { used }\end{array}$ & $a(\AA)$ & $c(\AA)$ & $V\left(\AA^{3}\right)$ \\
\hline Co-precipitation & SDS & 5.8705 & 23.1221 & 796.85 \\
& CTAB & 5.8490 & 23.3310 & 798.17 \\
& Tween-80 & 5.8655 & 23.2860 & 801.13 \\
& No surfactant & 5.8800 & 23.0822 & 798.05 \\
Reverse micelle & Triton X-100 & 5.8800 & 23.0240 & 796.04 \\
& & & & \\
\hline
\end{tabular}

\subsection{Scanning Electron Microscopy}

The morphology analysis of all $\mathrm{BaCa}_{2} \mathrm{Fe}_{16} \mathrm{O}_{27}$ hexaferrite samples were carried out using a scanning electron microscopy. Fig 3 (a-e) shows SEM images of normal and surfactant samples prepared by using a chemical co-precipitation and the reveres micelle techniques (calcinated at $950^{\circ} \mathrm{C}$ for 4 hours). It is seen from SEM images (Fig. 3 a,b,c) that Ba-Ca hexaferrites are well agglomerated to form the clusters of different sizes and shapes. The sample prepared in presence of sodium dodecyl sulfate shows (Fig. 3 d) separate particles of different sizes. One concludes that the type of surfactant plays a very crucial role in controlling the morphology of hexaferrite samples. In the sample prepared in the reverse micelle process the anisotropic crystal growth of hexaferrite precursor takes place in micelles and shows (Fig. 3e) elongated shape of particles with $75 \mathrm{~nm}$ in diameter and $180 \mathrm{~nm}$ in length.
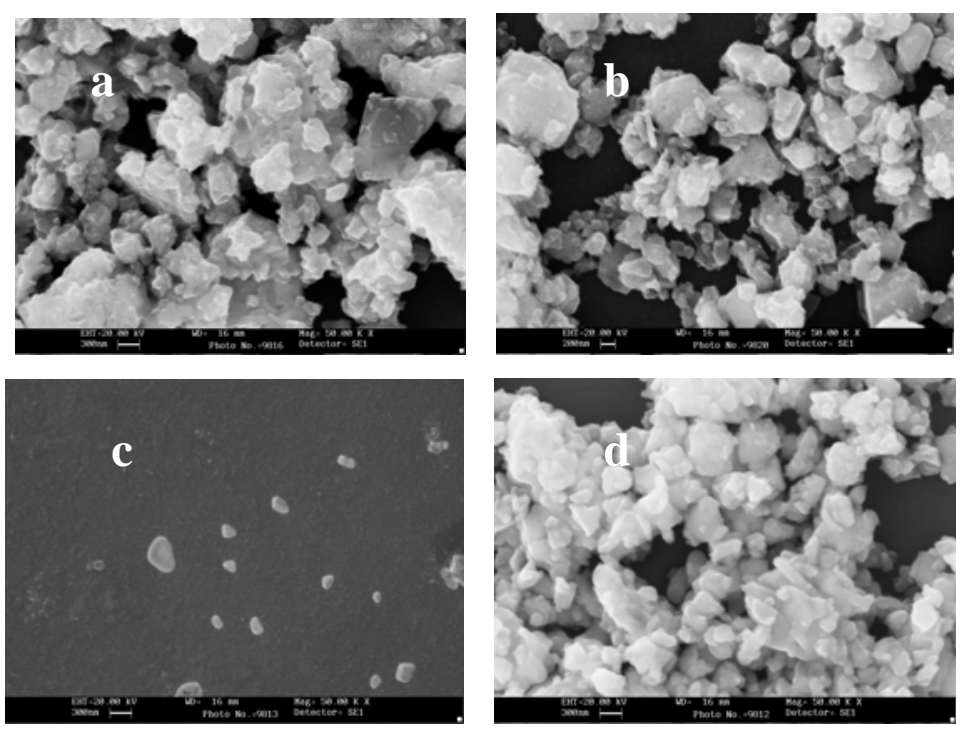


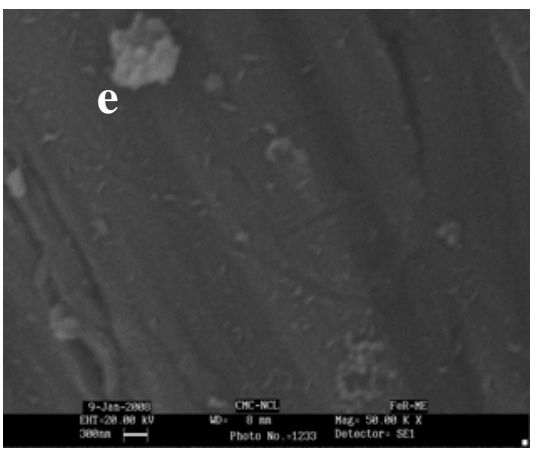

Fig. 3. SEM images of barium calcium hexferrite samples (calcined at $950^{\circ} \mathrm{C}$ for 4 hours) prepared by chemical co-precipitation (a) normal (no surfactant), (b) Tween 80, (c) SDS, (d) CTAB and (e) reverse micelle.

In order to determine the thermal stability TGA of sample was recorded, X-ray diffraction measurements were also recorded in order to check structural properties. The details are as follows:

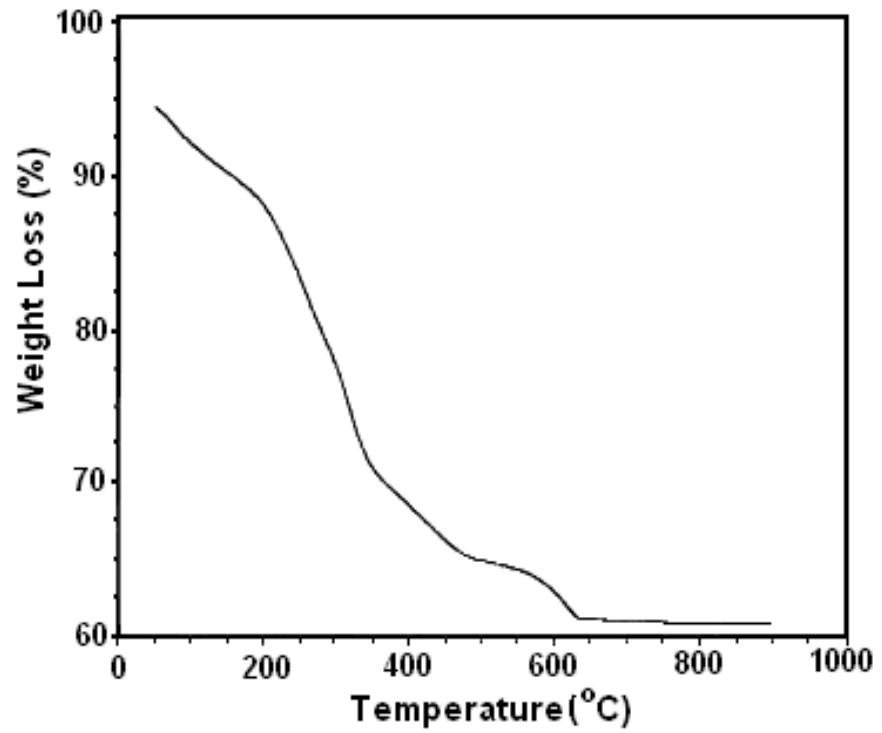

Fig. 4. TG Curve of Ba-Ca dried gel prepared by chemical co-precipitation technique.

\subsection{Thermo gravimetric analysis}

Fig. 4 shows thermo gravimetric analysis curve of the dried $\mathrm{Ba}-\mathrm{Ca}$ hexaferrite gel prepared by a co-precipitation route. TG curve shows three distinct steps of weight loss. 
The first step weight loss is between $50^{\circ} \mathrm{C}$ to $200^{\circ} \mathrm{C}(\sim 12.5 \mathrm{wt}$. \%) due to desorption of adsorbed water molecules. In the second step weight loss occurs between $200^{\circ} \mathrm{C}$ to $330^{\circ}$ C $(\sim 17.5$ wt. $\%)$, whereas in the third step the weight loss is less ( $\sim 8$ wt. $\%)$, in the temperature range between $330^{\circ} \mathrm{C}$ and $635^{\circ} \mathrm{C}$. It is seen from figure that above $635^{\circ} \mathrm{C}$ there is no weight loss, which confirms the high thermal stability of the sample synthesized by a co precipitation technique.

\subsection{Magnetic properties}

The field dependent magnetization of different powders of $\mathrm{Ba}-\mathrm{Ca}$ hexaferrites were measured at room temperature on a vibrating sample magnetometer with a maximum applied field of $15 \mathrm{kOe}$. The initial magnetization curves and hysteresis loops of the samples are shown in Figs. 5a, 5b and 5c. The magnetic parameters are listed in Table 2.

It is observed that the sample prepared in presence of sodium dodecyl sulfate shows higher saturation magnetization $\left(\mathrm{M}_{\mathrm{s}}\right)$, remnant magnetization $\left(\mathrm{M}_{\mathrm{r}}\right)$ and intrinsic coercivity $\left(\mathrm{H}_{\mathrm{c}}\right)$ than other samples. The values of $\mathrm{M}_{\mathrm{r}} / \mathrm{M}_{\mathrm{s}}$ for all the samples are about 0.5 , indicating that $\mathrm{BaCa}_{2} \mathrm{Fe}_{16} \mathrm{O}_{27}$ powder of single magnetic domains was produced [32].

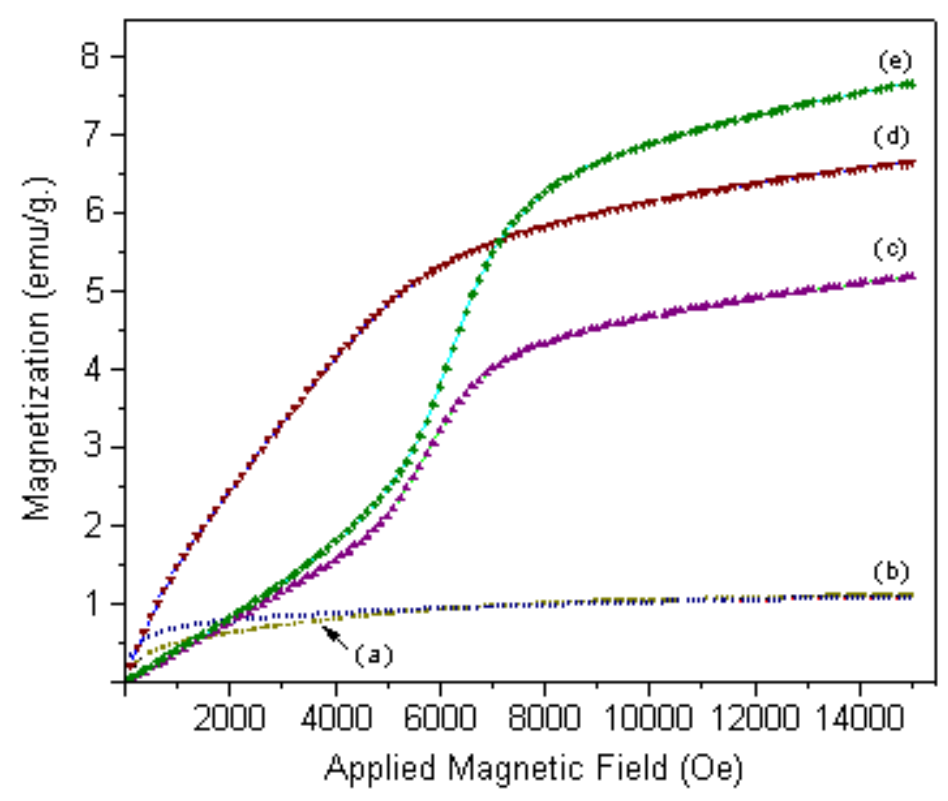

Fig. 5a. Initial Magnetization curves of the samples prepared by co precipitation (b-e) and reverse micelle (a) reverse micelle, (b) normal, (c) presence of Tween 80, (d) presence of CTAB, and (e) presence of SDS). 


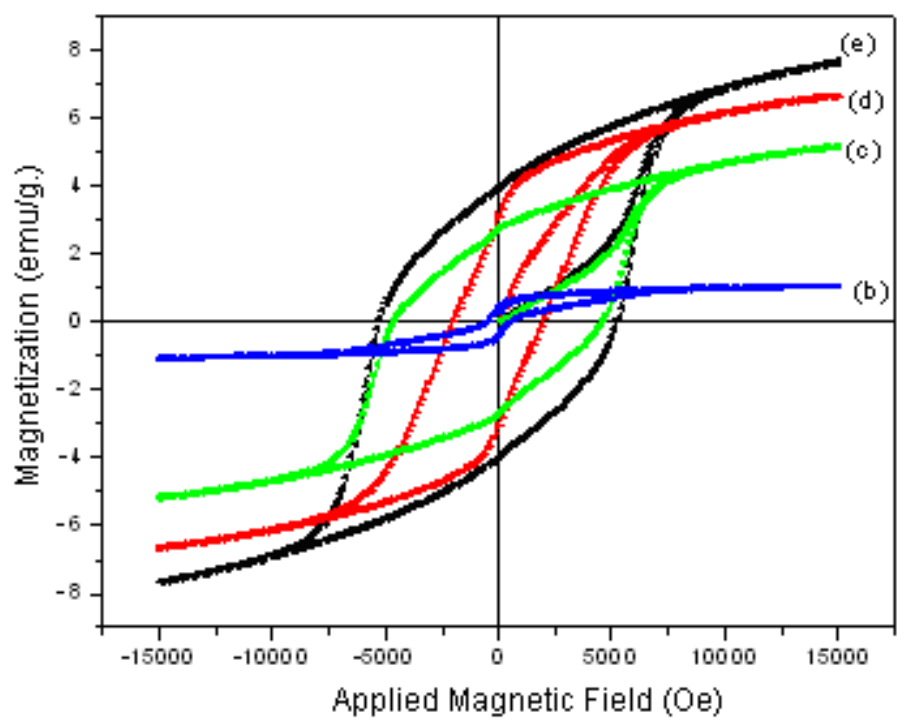

Fig. 5b. Hysteresis loops of the samples prepared by a co precipitation technique (b- normal, cpresence of Tween 80, d- presence of CTAB, e- presence of SDS).

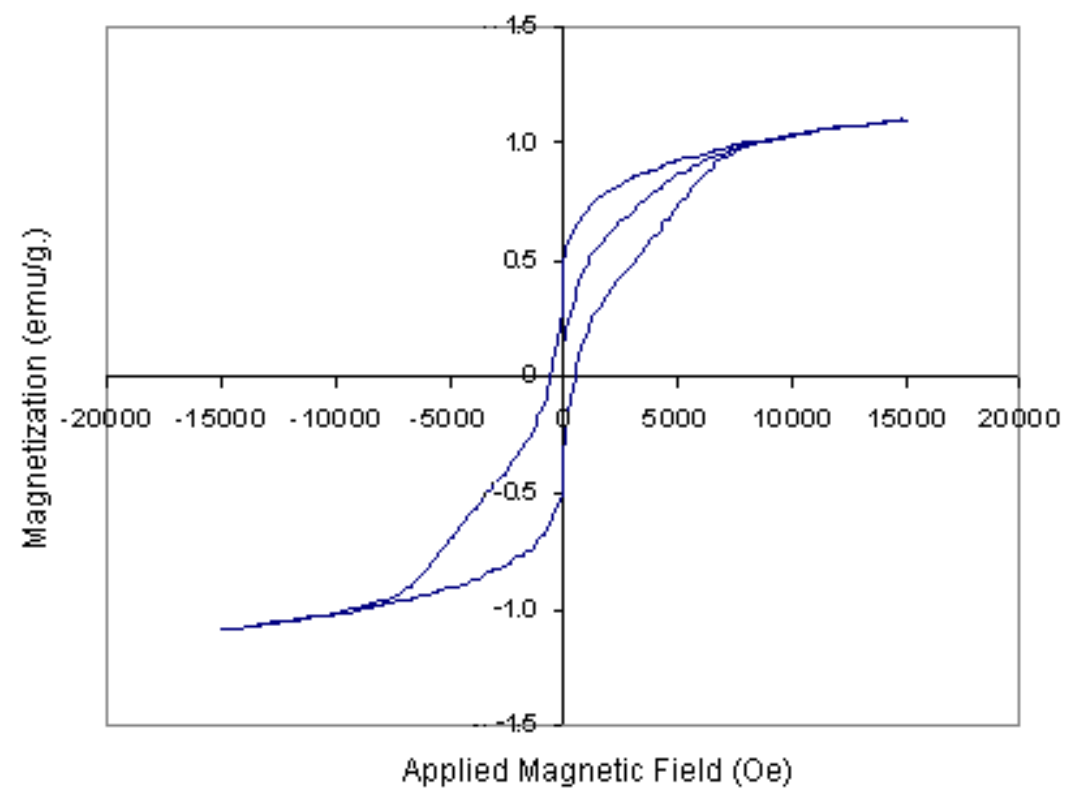

Fig. $5 c$. Hysteresis loop of the sample prepared by the reverse micelle technique. 
Table 2. Room temperature Magnetic parameters of $\mathrm{BaCa}_{2} \mathrm{Fe}_{16} \mathrm{O}_{27}$ hexaferrite powder prepared by a co precipitation and the reverse micelle techniques (Coercivity- $\mathrm{H}_{c}$, Saturation Magnetization- $\mathrm{M}_{\mathrm{s}}$, remanent Magnetization- $\mathrm{M}_{\mathrm{r}}$ and Magnetocrystalline anisotropy constant $\mathrm{K}$ measured at $15 \mathrm{kOe}$ ).

\begin{tabular}{lccccccc}
\hline $\begin{array}{l}\text { Preparation } \\
\text { Route }\end{array}$ & $\begin{array}{c}\text { Sample } \\
\text { code }\end{array}$ & $\begin{array}{c}\text { Surfactant } \\
\text { used }\end{array}$ & $\begin{array}{c}\mathrm{H}_{\mathrm{c}} \\
(\mathrm{Oe})\end{array}$ & $\begin{array}{c}\mathrm{M}_{\mathrm{s}} \\
(\mathrm{emu} / \mathrm{g} .)\end{array}$ & $\begin{array}{c}\mathrm{M}_{\mathrm{r}} \\
(\mathrm{emu} / \mathrm{g} .)\end{array}$ & $\begin{array}{c}\mathrm{M}_{\mathrm{r}} / \mathrm{M}_{\mathrm{s}} \\
\text { Co-precipitation }\end{array}$ & $\begin{array}{c}\mathrm{K} \\
\left(\mathrm{HA}^{2} / \mathrm{kg} .\right)\end{array}$ \\
& $\mathrm{A} 1$ & SDS & 5380 & 7.66 & 3.98 & 0.5196 & $3.26 \times 10^{-3}$ \\
& A2 & CTAB & 2000 & 6.65 & 3.13 & 0.4706 & $1.05 \times 10^{-3}$ \\
& A3 & Tween-80 & 475 & 5.20 & 2.70 & 0.5192 & $0.26 \times 10^{-3}$ \\
& A4 & No surfactant & 625 & 1.10 & 5.21 & 0.4763 & $0.41 \times 10^{-3}$ \\
$\begin{array}{l}\text { Reverse } \\
\text { micelle }\end{array}$ & A5 & Triton X-100 & 500 & 1.07 & 5.11 & 0.4775 & $0.42 \times 10^{-3}$ \\
& & & & & & & \\
\end{tabular}

The coercivity of particles is determined [33] by using magnetocrystalline anisotropy constant $\mathrm{K}$ and saturation magnetization.

$$
H_{c}=\frac{2 K}{\mu_{0} M_{S}}
$$

where, $\mu_{0}$ is the universal constant of permeability in free space equal to $4 \pi \times 10^{-7} \mathrm{H} / \mathrm{m}$. Magnetocrystalline anisotropy constant $\mathrm{K}$ can be calculated from Eq. 3. As shown in Table 2, the sample prepared in presence of sodium dodecyl sulfate shows the highest magnetocrystalline anisotropy constant. According to ref. [34], the energy barrier $\left(E_{A}\right)$ for rotation of magnetization orientation in a single domain particle is given by

$$
E_{A}=K V_{p} \sin ^{2} \theta
$$

where $V_{p}$ is the volume of the particle and $\theta$ is the angle between an applied field and the easy axis of the particle. The energy barrier $\left(E_{A}\right)$ is proportional to the product of $K V_{p}$, under the same magnetization direction. Using Eq. 1 one can estimate the order of energy barrier for all the samples that follow the order $E_{A 1}<E_{A 2}<E_{A 4}<E_{A 5}<E_{A 3}$.

The coercivity is considered as measure of the magnetic field strength necessary to achieve changes of the magnetization direction of material, low value of anisotropy of the material will give low activation energy barrier (observed in the sample prepared in presence of Polyethylene glycol sorbitan monooleate), and hence low applied field will be required for reversing the spin and hence low coercivity.

\subsection{Dielectric properties}

Fig .6 shows the frequency dependent dielectric behavior of normal sample prepared by chemical co precipitation route. There is a rapid decrease in dielectric constants (both real $\epsilon^{\prime}$ and complex $\left.\epsilon^{\prime \prime}\right)$ at lower frequency and attain constant value at higher frequencies. This behavior indicates dispersion due to Maxwell-Wagner [35, 36] type of interfacial polarization in well agreement with Koop's phenomenological theory [37]. The higher values of dielectric constants $\left(\epsilon^{\prime}\right.$ and $\left.\epsilon^{\prime \prime}\right)$ at lower frequencies are explained by using the 
concept of space charge polarization and due to heterogeneity in the sample [38]. The polarization at lower frequencies may result from the electron exchange between $\mathrm{Fe}^{3+} \leftrightarrow$ $\mathrm{Fe}^{2+}$ in hexaferrite lattice.

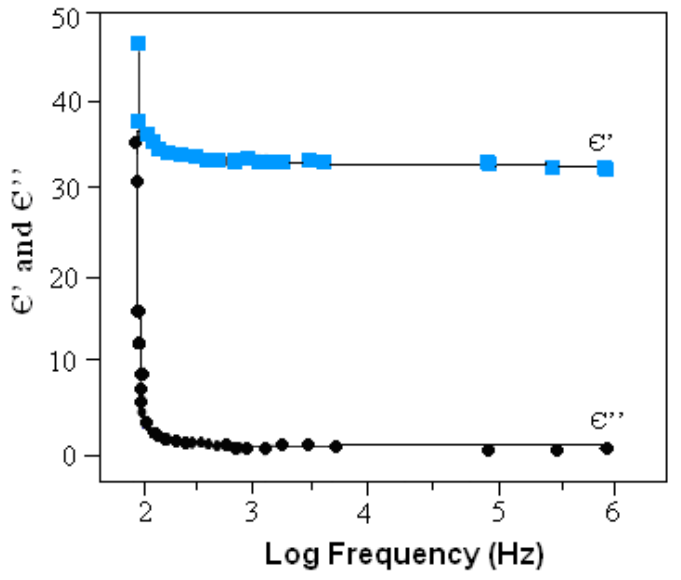

Fig. 6. The dielectric constants (real $\epsilon^{\prime}$ and complex $\epsilon^{\prime \prime}$ ) as a function of Log Frequency.

\section{Conclusions}

Barium calcium hexaferrite $\left(\mathrm{BaCa}_{2} \mathrm{Fe}_{16} \mathrm{O}_{27}\right)$ particles were synthesized by using the reverse micelle and chemical co precipitation techniques. It has been observed that the type of surfactant and method of preparation plays a crucial role in deciding the morphology and magnetization of the particles.

The observations from the scanning electron micrographs and vibrating sample magnetometer studies can be summarized as follows:

(i) A barium calcium hexaferrite powder is successfully synthesized by using a co precipitation technique with and without presence of three different surfactants (CTAB, SDS and Tween-80) and the reverse micelle technique.

(ii) Low saturation magnetization is observed in the sample prepared by the reverse micelle process and high saturation magnetization is obtained in the sample prepared with sodium dodecyl sulfate surfactant compared to the normal sample.

(iii) The sample prepared by the reverse micelle process shows nano dimension with single magnetic domains. However the normal sample and surfactant samples (prepared in presence of CTAB, Tween 80) show agglomerated clusters of different sizes and shapes. The sample prepared in presence of SDS shows separate, relatively small particles.

(iv) The sample prepared in presence of sodium dodecyl sulfate (SDS) exhibits larger magnetocrystalline anisotropy constant $\mathrm{K}$ and energy barrier $E_{A}$, calculated from Stoner-Wohlfarth theory.

(v) The form $\mathrm{BaCa}_{2} \mathrm{Fe}_{16} \mathrm{O}_{27}$ hexaferrite particles had maximum magnetic saturation (7.66 emu/gm) and wide intrinsic coercivity (475 Oe -5380 Oe). 


\section{Acknowledgements}

One of the authors (RBJ) is thankful to Inter University Acceleration Centre, New Delhi, for providing financial support in the form of Research project code no. UFUP43307/2008 and Department of Physics, Saurashtra University, Rajkot for helping in dielectric measurements.

\section{References}

1. H. Sato and T. Umeda, Mater. Trans. JIM 34, 76 (1993).

2. J. H. Lee, H. S. Kim, and C. W. Won, J. Mater. Sci. Lett. 15, 295 (1996). doi:10.1007/BF00591642

3. K. Haneda, C. Miyakawa, and K. Goto, IEEE Trans. Magn. 23, 3134 (1987). doi:10.1109/TMAG.1987.1065394

4. S. Capraro, J. P.Chatelon, M. Le Beree, H. Joisten, T. Rouiller, B. Bayard, D. Barbier, and J. J. Rousseau, J. Magn. Magn. Mater. e1805, 272 (2004).

5. J. X. Qiu and M. Y.Gu, J. Alloys Compd. 415, 209 (2006). doi:10.1016/j.jallcom.2005.03.125

6. P. Compbell, Permanent Magnet Materials and their Applications (Cambridge University Press, Cambridge, 1994.)

7. M. P. Sharrock and L. Joshepson, IEEE Trans. Magn. 22, 727 (1986). doi:10.1109/TMAG.1986.1064545

8. M. H. Keyder and J. Magn. Magn. Mater. 83, 1 (1990). doi:10.1016/0304-8853(90)90410-R

9. T. Kagotani, D. Fujiwara, S. Sugimoto, K. Inomata, and M. Homma, J. Magn. Magn. Mater. e1813, 272 (2004).

10. T. Nakamura, T. Tsutaoka, and K. Hatakeyama, J. Magn. Magn. Mater. 138, 319 (1994). doi:10.1016/0304-8853(94)90054-X

11. O. Kabo, T. Ido, and H. Yokoyama, IEEE Trans. Magn. 18, 1122 (1982). doi:10.1109/TMAG.1982.1062007

12. W. Zhong, W. P. Ding, and N. Zhang, J. Magn. Magn. Mater. 168, 196 (1997). doi:10.1016/S0304-8853(96)00664-6

13. S. E. Jacobo, C. Domingo-Pascual, and R. Rodriguez-Clement, J. Mater. Sci. 32, 1025 (1997). doi:10.1023/A:1018582423406

14. K. Haneda, C. Miyakawa, and H. Kojima, J. Am. Ceram. Soc. 57, 354 (1974). doi:10.1111/j.1151-2916.1974.tb10921.x

15. A. Ataie, M. R. Piramoon, I. R. Harris, and C. B. Ponton, J. Mater. Sci. 30, 5600 (1995). doi:10.1007/BF00356692

16. H. Kumazawa, Y. Maedaand, and E. Sada, J. Mater. Sci. Lett. 14, 68 (1995). doi:10.1007/BF02565290

17. V. Pillai, P. Kumar, and D. O. Shah, J. Magn. Magn. Mater. 116, 299 (1992). doi:10.1016/0304-8853(92)90105-W

18. V. Pillai, P. Kumar, M. S. Multani, and D. O. Shah, Colloids Surf. A 80, 69 (1993). doi:10.1016/0927-7757(93)80225-4

19. F. Licci and T. Besagni, IEEE Trans. Magn. 20, 1639 (1984). doi:10.1109/TMAG.1984.1063279

20. V. Pallai, P. Kumar, and D. O. Shah. J. Magn. Magn. Mater. L 299, 116 (1992).

21. X. Y. Liu, J. Wang, L. M. Gan, S. C. Ng, and J. Ding, J. Magn. Magn. Mater. 184, 344 (1998). doi:10.1016/S0304-8853(97)01141-4

22. C. R. Vestal, Z. J. Zhang, Nano Lett. 3 (12), 1739 (2003). doi:10.1021/nl034816k

23. C. Liu, B. S. Zou, A. J. Rondinone, and Z. J. Zhang, J. Phys. Chem. B 10, 1141 (2000). doi:10.1021/ip993552g

24. J. Rondinone, C. Liu, and Z. J. Zhang, J. Phys. Chem. B 105, 7967 (2001). doi:10.1021/jp011183u 
25. R. Vestal, Z. J. Zhang, J. Am. Chem. Soc. 125, 9828 (2003). doi:10.1021/ja035474n

26. M. Han, C. R. Vestal, and Z. J. Zhang, J. Phys. Chem. B 108, 583(2004). doi:10.1021/jp035966m

27. M. A. Lopez-Quintela and J. Rivas, J. Colloid Interface Sci. 158, 446 (1993). doi:10.1006/jcis.1993.1277

28. R. B. Jotania, R. B. Khomane, C. C. Chauhan, S. K. Menon, and B. D. Kulkarni, J. Magn. Magn. Mater. 320, 1095 (2008). doi:10.1016/j.jmmm.2007.10.032

29. F. K. Lotgering and P. H. G. M. Vromans, J. Am. Ceram. Soc. 60, 416 (1977). doi:10.1111/j.1151-2916.1977.tb15524.x

30. J. Smith and H. P. J. Wijn, Ferrites (Philips' Technical Library, Eindhoven, 1959).

31. K. Jisheng, L.Huaixian, and D.Youwei, J. Magn. Magn. Mater. 31, 801 (1983). doi:10.1016/0304-8853(83)90692-3

32. H. F. Yu and K. C. Huang, J. Magn. Magn. Mater. 260, 455 (2003). doi:10.1016/S03048853(02)01389-6

33. Q. Song and Z. Zhang, J. Am. Chem. Soc. 126, 6164 (2004). doi:10.1021/ja049931r

34. E. C. Stoner, E. Wohlfarth, and P. Philos, Trans. Royal. Soc. London A 240, 599 (1948).

35. J. C. Maxwell, Electricity and Magnetism (Oxford University Press, London, 1973).

36. K. Wagne and W. Ann. Phys. 40, 818 (1993).

37. C. G. Koops, Phys. Rev. 83, 121 (1951). doi:10.1103/PhysRev.83.121

38. D. C. Agarwal, Asian J. Phys. 6, 108 (1997). 